\title{
Effects of sea-buckthorn leaves on performance and serum metabolic profiles in Altay lambs
}

\author{
Yan-Feng Liu ${ }^{1,2^{*}}$, Jun-Li Niu ${ }^{1 *}$, Shu-ZhenTang ${ }^{2}$, Cun-Xi Nie ${ }^{1}$, Wen-Ju Zhang ${ }^{1 \#}$, Chun-Yan Guo ${ }^{1}$, \\ Guang-Tian Hou' ${ }^{2}$, Wen-Qi Wang ${ }^{2} \&$ Wen-Xia Ge ${ }^{1}$ \\ ${ }^{1}$ College of Animal Science and Technology, Shihezi University, P R China \\ ${ }^{2}$ Feed Researchlnstitute, Xinjiang Academy of Animal Science, P R China \\ ${ }^{*}$ Contributed equally to this study
}

(Received 14 November 2018; Accepted 14 June 2019; First published online 11 August 2019)

Copyright resides with the authors in terms of the Creative Commons Attribution 4.0 South African License.
See: http://creativecommons.org/licenses/by/4.0/za
Condition of use: The user may copy, distribute, transmit and adapt the work, but must recognize the authors and the South African
Journal of Animal Science.

\begin{abstract}
In this study, the effects of sea-buckthorn (Hippophae rhamnoides L.) leaves (SL) on the biochemical parameters and metabolomic profiling in Altay lamb (Ovis aries) were observed. Sixty six-month-old male Altay lambs (body weight $28.0 \pm 3.5 \mathrm{~kg}$ ) were randomly assigned to four groups $(\mathrm{n}=15)$. The experimental groups were named as CON, 2.5\%, 5.0\% and 7.5\%. The group CON, contained animals fed with a basal diet. Animals of the other groups were fed a treatment diet consisting of 2.5\% (Group 2.5\%), 5.0\% (Group $5.0 \%$ ) and $7.5 \%$ (Group 7.5\%) SL. The experimental period lasted 56 days. The results showed that the average daily gain (ADG) and average daily feed intake (ADFI) increased with the increase in the levels of dietary SL. Dietary SL showed a direct relationship with total protein (TP), albumin, globulin and total cholesterol (TC) content of the experimental animals. However, an indirect relationship was observed between dietary SL and the concentration of urea nitrogen (UN). The concentrations of glucose, high-density lipoprotein cholesterol (HDL-C) and low-density lipoprotein cholesterol (LDL-C) showed quadratic change. Additional changes occurred in the endogenous metabolites involving multiple pathways. The pathways were tricarboxylic acid (TCA) cycle, the metabolism of protein and amino acid and the metabolism of fatty acid and steroid. The changes in metabolites primarily revealed an increase in amino acids and carbohydrates and a decrease in lipid metabolites. These findings provide a comprehensive insight into the effects of the metabolic aspects of sea-buckthorn leaves on Altay lambs. In addition, the present research results provide a better understanding to the development and utilization of sea-buckthorn as a healthy additive for small ruminant production.
\end{abstract}

Key words: Hippophae rhamnoides L., lamb, metabolomics, growth performance, serum parameters \#Corresponding author: zhangwj1022@sina.com

\section{Introduction}

Sea-buckthorn (Hippophae rhamnoides L., Fam. Elaeagnaceae), is a hardy branched and thorny nitrogen-fixing deciduous shrub (Yildiz et al., 2012). The plant is native to and widespread throughout the north-western Europe and Central Asia to the Altai Mountains. It is further distributed in the western and northern China, and the northern Himalayas (Heinz et al., 1998; Zhao et al., 2017). All parts of the plant are considered rich in biologically active substances. Those are flavonoids, carotenoids, steroids (erogosterol, stigmasterol, lanosterols, and amyrins), vitamins C, E and K, fatty acid, and some essential amino acids (Rousi et al., 1971; Beveridge et al., 1999; Srivastava et al., 2013; Guliyev et al., 2004). These compounds have beneficial effects on human health, such as anti-atherogenic, antioxidant, anti-cancer, and anti-bacterial effects (Suomelaet al., 2006; Yuan et al., 2016; Wang et al., 2018).

Sea-buckthorn leaves are rich in nutrients and bioactive substances. It is used widely throughout the world because of its high medicinal and nutritional properties (Li et al., 2007). In The People's Republic of China, sea-buckthorn covers an area of more than 500,000 ha (Chen et al., 2010). The supplementation $(0.1 \%)$ of sea-buckthorn extraction in the diets of piglets has been found to reduce fat deposition (Liu et al., 2008). However, little information is known about the effects of sea-buckthorn leaves on small ruminants. 
Metabolomics is a powerful approach to delineating the global metabolic profiling of living organisms. It also acts as the basis of capturing the subtle metabolic alterations associated with physiological and pathological stimulations. It has been widely used in drug toxicity detection (Oresic et al., 2009), disease diagnosis and animal model research (Gupta et al., 2005). Metabolomics also contributes in feed nutrition and livestock production (Nie et al., 2015; Zhang et al., 2017). Recent publications on metabolomics have focused on the relationship between metabolite changes, overall biology, and biomarkers (Nicholson et al., 1999). Wood et al. (2010) reported that dietary docosahexaenoic acid (DHA) supplementation altered the selected constituents of the physiological brain and the plasma endocannabinoid metabolomes. DHA also had produced effects on endocannabinoid-related lipid species, indices of psychobehavioral and physical health.

Altay lamb (Ovis aries) is an ancient shag lamb breed that originated in the Altay region of Xinjiang, China. It is an important source of meat which provides nutrition and generates income to the local people.

The authors, therefore, conducted this study to analyse the performance and serum metabolic alterations caused by sea-buckthorn leaves in Altay lamb. This will provide a theoretical basis for the development and utilization of sea-buckthorn leaves as a healthy additive for small ruminant production.

\section{Materials and Methods}

For the present research, leaves of sea-buckthorn (SL) were collected in August during the fruiting period from Qinghe County (Xinjiang, China). The SL samples were dried under natural conditions for six days until the moisture content was less than $25 \%$. The diameters of the stems were less than $1 \mathrm{~cm}$. After drying, the SL were thoroughly mixed with other dietary components in a Total mixed ration mixer and fed to the experimental lambs. The chemical compositions of the SL were analysed for dry matter (DM), crude protein, ether extract, crude ash, neutral detergent fibre, acid detergent fibres, calcium, and phosphorus (AOAC, 2000). Gross energy content of the SL was determined using a bomb calorimeter Parr® 6200 (Table 1).

Table 1 Chemical composition of sea-buckthorn leaves

\begin{tabular}{lc}
\hline Items & Content \\
\hline Dry matter & 92.62 \\
Crude protein, \% of DM & 11.73 \\
Ether extract, \% of DM & 5.05 \\
Crude ash, \% of DM & 9.14 \\
Neutral detergent fibre, \% of DM & 29.94 \\
Acid detergent fibres, \% of DM & 20.34 \\
Calcium, \% of DM & 0.41 \\
Phosphorus, \% of DM & 0.18 \\
Gross energy, MJ/Kg & 15.70 \\
\hline
\end{tabular}

Sixty six-month-old male Altay lambs (body weight $28.0 \pm 3.5 \mathrm{~kg}$ ) were randomly assigned to four groups ( 3 replicates of 5 lambs in each group). For the experimental purpose, the groups were named CON (control i.e., $0 \%$ ), $2.5 \%, 5.0 \%$ and $7.5 \%$. The group CON was fed with $100 \%$ wheat straw i.e., the basal diet. While the lambs of groups $2.5 \%, 5.0 \%$ and $7.5 \%$ received a feed containing $2.5,5.0$ and $7.5 \%$ replacement of the basal diet by SL, respectively. The experimental period lasted for 56 days including seven days as adaptation phase. The diets were formulated according to the nutrient recommendations for small ruminants (NRC 2007) (Table 2). The lambs were housed at moderate temperature $\left(15.78 \pm 0.61^{\circ} \mathrm{C}\right)$ and humidity $(60.12 \pm 1.80 \%)$. They had free access to feed and drink water in the rearing period. The animal care and use protocols were approved by the Animal Welfare Committee of Shihezi University.

During the experiment, the refused feed was weighed daily for each group. The lambs were weighed individually at the beginning and end of the trial. At the end of the experiment, six lambs per group whose weight was close to the average weight of the group were randomly selected for blood collection. Blood samples $(5 \mathrm{~mL})$ were collected from the jugular veins after 12 hours' food deprivation. All blood samples were centrifuged at $2700 \times \mathrm{g}$ at $4^{\circ} \mathrm{C}$ for $15 \mathrm{~min}$ to isolate the serum, which was separated into sterilized 
tubes and stored at $-80^{\circ} \mathrm{C}$ until further analysis.

Table 2 Composition and nutrient levels of four diets containing various levels of SL (CON, 2.5\%, 5.0\%, and 7.5\%) (based on air-dry matter)

\begin{tabular}{|c|c|c|c|c|}
\hline \multirow{2}{*}{ Items } & \multicolumn{4}{|c|}{ Content $^{1}$} \\
\hline & $\mathrm{CON}$ & $2.5 \%$ & $5.0 \%$ & $7.5 \%$ \\
\hline \multicolumn{5}{|l|}{ Ingredient, $\%$ of DM } \\
\hline Alfalfa & 33.33 & 33.33 & 33.33 & 33.33 \\
\hline Wheat straw & 25.00 & 22.50 & 20.00 & 17.50 \\
\hline Sea-buckthorn leaves & 0.00 & 2.50 & 5.00 & 7.50 \\
\hline Corn & 23.75 & 23.75 & 23.75 & 23.75 \\
\hline Corn gluten meal & 0.83 & 0.83 & 0.83 & 0.83 \\
\hline Wheat bran & 3.25 & 3.25 & 3.25 & 3.25 \\
\hline Sunflower meal & 2.08 & 2.08 & 2.08 & 2.08 \\
\hline Cottonseed meal & 5.83 & 5.83 & 5.83 & 5.83 \\
\hline DDGS & 2.50 & 2.50 & 2.50 & 2.50 \\
\hline Limestone & 1.25 & 1.25 & 1.25 & 1.25 \\
\hline $\mathrm{CaHPO}_{4}$ & 0.63 & 0.63 & 0.63 & 0.63 \\
\hline $\mathrm{NaCl}$ & 0.25 & 0.25 & 0.25 & 0.25 \\
\hline Premix $^{2}$ & 1.30 & 1.30 & 1.30 & 1.30 \\
\hline \multicolumn{5}{|l|}{ Chemical composition $^{3}$} \\
\hline Dry matter & 90.70 & 90.76 & 90.82 & 90.88 \\
\hline Metabolizable energy, MJ/kg & 8.80 & 8.81 & 8.82 & 8.84 \\
\hline Crude protein, $\%$ of DM & 13.60 & 13.82 & 14.04 & 14.25 \\
\hline Crude fibre, $\%$ of DM & 19.30 & 19.00 & 18.71 & 18.41 \\
\hline Calcium, \% of DM & 0.90 & 0.91 & 0.91 & 0.92 \\
\hline Phosphorus, $\%$ of DM & 0.30 & 0.30 & 0.31 & 0.31 \\
\hline
\end{tabular}

${ }^{1} \mathrm{CON}$ : $2.5 \%, 5.0 \%$, and $7.5 \%$ mean that supplementation of SL was $0 \%, 2.5 \%, 5.0 \%$, and $7.5 \%$ and replaced the equivalent amounts of wheat straw, respectively

${ }^{2}$ Vitamin A: $15000 \mathrm{IU}$, vitamin D: $5000 \mathrm{IU}$, vitamin E: $50 \mathrm{mg}$, iron: $90 \mathrm{mg}$, copper: $12 \mathrm{mg}$, manganese: $50 \mathrm{mg}$, zinc: 110 $\mathrm{mg}$, selenium: $0.3 \mathrm{mg}$, cobalt: $0.5 \mathrm{mg}$ (g/kg diet)

${ }^{3}$ Metabolizable energy $=[($ digestible organic matter, $\mathrm{g} / \mathrm{kg} \mathrm{DM}) / 1000] \times 18.5 \times 0.81$, according to ARC (1990). The nutrient levels are actual measured values, except ME value, which was calculated.

Total protein (TP), albumin, globulin, urea nitrogen (UN), glucose, creatinine, total cholesterol (TC), triglycerides (TG), high-density lipoprotein cholesterol (HDL-C), and low-density lipoprotein cholesterol (LDLC) were assayed using automatic biochemical analyser kits by Abbott AerosetC4000 (Abbott Laboratories, Chicago, USA).

The serum samples were thawed $(50 \mu \mathrm{L})$ at room temperature and dried in GC (gas chromatograph) vials in moderate nitrogen gas. Methoxyamine $(30 \mu \mathrm{L})$ in pyridine $(20 \mathrm{mg} / \mathrm{mL})$ was added and mixed vigorously for 30 seconds with the help of a vortex mixer. Methoximation reaction was performed at $37^{\circ} \mathrm{C}$ for 90 min, and then $30 \mu \mathrm{L}$ of BSTFA with $1 \%$ TMCS was added to the sample as a catalyst. Finally, the solution was shaken for $60 \mathrm{~min}$ at $70^{\circ} \mathrm{C}$, and then cooled for $30 \mathrm{~min}$ at room temperature for gas chromatographymass spectrometry (GC-MS) analysis.

All samples $(1 \mu \mathrm{L})$ were analysed with an Agilent $7890 \mathrm{~A} / 5975 \mathrm{C} \mathrm{GC} / \mathrm{MS}$ system with a capillary column (HP-5MS, $30 \mathrm{~m} \times 0.25 \mathrm{~mm} \times 0.25 \mu \mathrm{m}$ ) (Agilent Technologies, Shanghai, China). Helium gas was used as the carrier gas through the column at a flow rate of $1 \mathrm{~mL} / \mathrm{min}$. The injector, MS quadrupole, and ion source temperature were $280^{\circ} \mathrm{C}, 150^{\circ} \mathrm{C}$ and $230^{\circ} \mathrm{C}$, respectively. The initial temperature was kept at $80^{\circ} \mathrm{C}$ for $2 \mathrm{~min}$, and then raised to $320^{\circ} \mathrm{C}$ at a speed of $10^{\circ} \mathrm{C}$ per min, which was maintained for 6 min. The masses were 
acquired in full scan mode from mass-to-charge $(\mathrm{m} / \mathrm{z})$ ratio of 50:500.

All MS data were analysed by AMDIS (automated mass spectral deconvolution and identification system) software for peak deconvolution, and NIST mass spectral library was used for peak identification.

The data were analysed using the PROC MIXED procedure of SAS (SAS Institute Inc., Cary, NC). The model included treatment and block as fixed effects. The results were reported as least squares means. Contrasts were used to test the linear, quadratic and cubic changes as affected, because of the increasing amount of dietary SL. Diagnostics were examined for the homogeneity and normality of the residuals and were not of concern for the variables studied here. Significant differences were declared at $P<0.05$, and the trends were reported at $0.05 \leqslant P<0.10$. Principal component analysis (PCA) and partial least squaresdiscriminant analysis (PLS-DA) were performed via Simca-P 11.5 software (Umetrics, AB, Sweden). The variable significance in the projection (VIP) values $(\mathrm{VIP}>1.0)$ and $t$-test $(P<0.05)$ were both employed to find differentially expressed metabolites.

\section{Results}

The effect of SL on growth performance of Altay lamb is presented in Table 3. Neither the initial nor the final body weight of lamb in this study was influenced by the treatments. ADG increased linearly $(P<0.05)$ with increasing SL levels. The values were compared with those from CON. The ADG in lambs fed with $5.0 \%$ SL and $7.5 \%$ SL increased $(P<0.05)$ by $8.16 \%$ and $7.85 \%$, respectively. However, those that were fed $2.5 \%$ SL did not differ in their ADG compared with the CON group. ADFI was linearly increased $(P<0.01)$ with rising SL levels. The ADFI was higher in the $5.0 \%$ SL than in CON $(P<0.05)$. Additionally, no difference was observed in feed conversion ratio (FCR) among treatments.

Table 3 Effect of sea-buckthorn leaves on production performance of Altay lamb

\begin{tabular}{|c|c|c|c|c|c|c|c|c|c|}
\hline \multirow{2}{*}{ Items } & \multicolumn{4}{|c|}{ Treatments $^{1}$} & \multirow{2}{*}{ SEM } & \multicolumn{4}{|c|}{$P$-value } \\
\hline & CON & $2.5 \%$ & $5.0 \%$ & $7.5 \%$ & & Treatment & Linear & Quadratic & Cubic \\
\hline Initial bodyweight, kg & 28.08 & 28.27 & 28.60 & 28.34 & - & - & - & - & - \\
\hline Final bodyweight, kg & 33.46 & 33.44 & 34.86 & 34.31 & 0.785 & 0.902 & 0.502 & 0.782 & 0.883 \\
\hline Average daily gain, g/d & $128.7^{\mathrm{b}}$ & $128.0^{\mathrm{b}}$ & $139.2^{\mathrm{a}}$ & $138.8^{\mathrm{a}}$ & 1.966 & 0.007 & 0.005 & 0.730 & 0.022 \\
\hline Average daily feed intake, $\mathrm{kg} / \mathrm{d}$ & $1.00^{b}$ & $0.98^{\mathrm{b}}$ & $1.06^{\mathrm{a}}$ & $1.01^{\mathrm{ab}}$ & 0.005 & $<.001$ & $<.001$ & 0.001 & 0.550 \\
\hline Feed conversion ratio & 7.77 & 7.65 & 7.64 & 7.25 & 0.049 & 0.097 & 0.063 & 0.807 & 0.664 \\
\hline
\end{tabular}

${ }^{1} \mathrm{CON}, 2.5 \%, 5.0 \%$, and $7.5 \%$ mean that supplementation of SL was $0 \%, 2.5 \%, 5.0 \%$, and $7.5 \%$ replaced the equivalent amounts of wheat straw, respectively

${ }^{a, b}$ Means within the same row with different lowercase letters indicate significant difference $(P<0.05)$

With the increasing amount of dietary SL, TP, albumin, globulin and TC increased linearly $(P<0.05)$ (Table 4). The concentration of glucose, HDL-C and LDL-C increased in a quadratic way $(P<0.05)$ with increasing dietary SL levels (Table 4). However, dietary treatments had no effect on the concentrations of creatinine and TG in the blood $(P>0.05)$.

PCA models with good clusters of both the control and SL groups and no strong outliers were observed (Figure 1). These presented apparent groupings, with only partial overlapping between the control and SL data. To obtain improved model transparency and interpretability, PLS-DA and chemometric analysis were performed. All these helped to screen differential variables. These showed a clear separation between the CON and SL groups without any overlap (Figure 1). So, one predictive component and two orthogonal components with satisfactory modelling and predictive abilities $R^{2}(X)=0.392, R^{2}(Y)=0.558$, and $Q^{2}($ cum $)$ $=0.189$ were produced. On the basis of the overall analyses, the results indicated that the predictive capabilities of the PLS-DA models of the GC-MS data were reliable.

GC-MS analyses identified a total of 17 metabolic components mainly from amino acid, carbohydrate and lipid super classes (Table 5). The metabolic alterations between the CON and SL groups have been listed in Table 5. SL group-induced alterations in the amino acid-related metabolites were valine, alanine and glycine. Concentrations of these metabolites were increased in SL groups compared with the CON $(P<0.05)$. Valine and alanine were increased in SL groups compared with the CON group $(P<0.05)$, and glycine was decreased $(P<0.05)$. From lipids, compared with CON, $\beta$-Hydroxybutyric acid, palmitic acid, oleic acid, oleic 
acid amide, octadecanamide, and cholesterol were decreased but linoleic acid and stearic acid were increased $(P<0.05)$.

Table 4 Effect of sea-buckthorn leaves on serum parameters of Altay lamb

\begin{tabular}{|c|c|c|c|c|c|c|c|c|c|}
\hline \multirow{2}{*}{ Items $^{2}$} & \multicolumn{4}{|c|}{ Treatments $^{1}$} & \multirow{2}{*}{ SEM } & \multicolumn{4}{|c|}{$P$-value } \\
\hline & CON & $2.5 \%$ & $5.0 \%$ & $7.5 \%$ & & Treatment & Linear & Quadratic & Cubic \\
\hline TP, g/l & $69.22^{b}$ & $72.33^{\mathrm{ab}}$ & $77.31^{\mathrm{a}}$ & $81.76^{\mathrm{a}}$ & 1.160 & 0.001 & $<.001$ & 0.915 & 0.688 \\
\hline Albumin,g/l & $24.60^{a b}$ & $24.47^{b}$ & $26.38^{\mathrm{a}}$ & $26.52^{\mathrm{a}}$ & 0.345 & 0.038 & 0.022 & 0.784 & 0.263 \\
\hline Globulin, g/l & $44.62^{c}$ & $47.87^{\mathrm{bc}}$ & $50.93^{\mathrm{ab}}$ & $55.25^{\mathrm{a}}$ & 1.067 & 0.002 & 0.002 & 0.774 & 0.940 \\
\hline Alb/Glo & $0.56^{\mathrm{a}}$ & $0.51^{\mathrm{ab}}$ & $0.52^{\mathrm{a}}$ & $0.49^{\mathrm{b}}$ & 0.013 & 0.044 & 0.048 & 0.474 & 0.486 \\
\hline UN, mmol/l & $10.46^{\mathrm{a}}$ & $9.51^{\mathrm{ab}}$ & $9.28^{\mathrm{a}}$ & $8.57^{\mathrm{b}}$ & 0.203 & 0.008 & 0.001 & 0.742 & 0.409 \\
\hline Glucose, mmol/l & $3.97^{\mathrm{ab}}$ & $4.08^{\mathrm{ab}}$ & $4.22^{\mathrm{a}}$ & $3.69^{b}$ & 0.075 & 0.046 & 0.338 & 0.036 & 0.076 \\
\hline Creatinine, $\mu \mathrm{mol} / \mathrm{l}$ & 59.50 & 58.83 & 61.83 & 63.17 & 0.119 & 0.643 & 0.219 & 0.878 & 0.860 \\
\hline TG, mmol/l & 0.25 & 0.24 & 0.27 & 0.20 & 0.015 & 0.917 & 0.832 & 0.820 & 0.546 \\
\hline $\mathrm{TC}, \mathrm{mmol} / \mathrm{l}$ & $1.00^{\mathrm{b}}$ & $1.05^{\mathrm{b}}$ & $1.18^{\mathrm{ab}}$ & $1.28^{\mathrm{a}}$ & 0.031 & 0.018 & 0.003 & 0.259 & 0.955 \\
\hline $\mathrm{HDL}-\mathrm{C}, \mathrm{mmol} / \mathrm{l}$ & $0.53^{\mathrm{ab}}$ & $0.51^{b}$ & $0.50^{\mathrm{b}}$ & $0.62^{\mathrm{a}}$ & 0.015 & 0.026 & 0.019 & 0.021 & 0.562 \\
\hline LDL-C, mmol/l & $0.23^{\mathrm{b}}$ & $0.35^{\mathrm{a}}$ & $0.34^{\mathrm{a}}$ & $0.31^{\mathrm{ab}}$ & 0.015 & 0.013 & 0.067 & 0.019 & 0.092 \\
\hline
\end{tabular}

${ }^{1} \mathrm{CON}, 2.5 \%, 5.0 \%$, and $7.5 \%$ mean that supplementation of SL was $0 \%, 2.5 \%, 5.0 \%$, and $7.5 \%$ replaced the equivalent amounts of wheat straw, respectively

${ }^{2}$ TP: total protein; UN: urea nitrogen; TG: triglycerides; TC: total cholesterol; HDL-C: high density lipoprotein cholesterol; LDL-C: low density lipoprotein cholesterol

$a, b$ Means within the same row with different lowercase letters indicate significant difference $(P<0.05)$

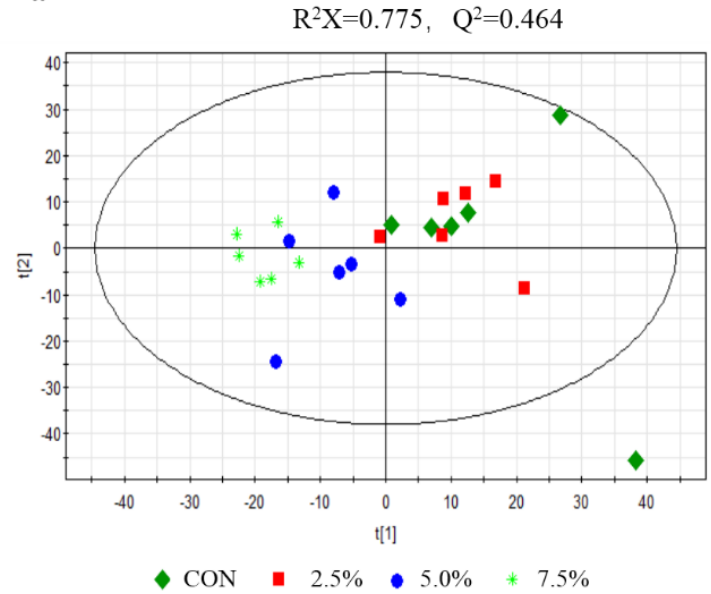

b

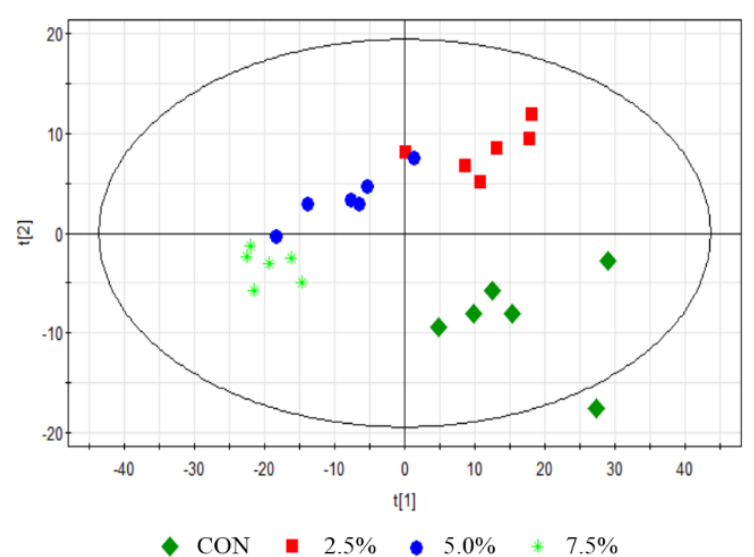

Figure 1 PCA and PLS-DA score plots derived from the GC-MS metabolite profiles of serum samples for lambs fed increasing levels of SL in their diets.

CON, 2.5\%, 5.0\%, and 7.5\% mean that supplementation of SL was $0 \%, 2.5 \%, 5.0 \%$, and $7.5 \%$ replaced the equivalent amounts of wheat straw, respectively.

a: Score plot for the PCA model of control group and SL groups. b: Score plot for the PLS-DA model of control group and SL groups. 
Table 5 Significantly different metabolites between CON and SL supplemented group ${ }^{1}$

\begin{tabular}{|c|c|c|c|c|c|c|c|c|c|}
\hline \multirow[b]{2}{*}{ Super class } & \multirow[b]{2}{*}{ Metabolites } & \multirow{2}{*}{$\mathrm{RT}(\min )^{2}$} & \multirow[b]{2}{*}{$\mathrm{m} / \mathrm{z}^{3}$} & \multirow{2}{*}{$\begin{array}{l}\text { Fold }(2.5 \% / \\
\text { CON })^{4}\end{array}$} & \multirow{2}{*}{$\begin{array}{l}\text { Fold }(5.0 \% / \\
\text { CON) }\end{array}$} & \multirow{2}{*}{$\begin{array}{l}\text { Fold }(7.5 \% / \\
\text { CON) }\end{array}$} & \multicolumn{3}{|c|}{$P$-value ${ }^{5}$} \\
\hline & & & & & & & $2.5 \% / \mathrm{CON}$ & $\begin{array}{l}5.0 \% / \\
\text { CON }\end{array}$ & $\begin{array}{l}7.5 \% / \\
\text { CON }\end{array}$ \\
\hline Amino acid & Valine & 7.151 & 87.050 & 0.501 & 0.896 & 0.807 & 0.006 & 0.018 & 0.004 \\
\hline Amino acid & Alanine & 7.554 & 102.060 & 1.270 & 1.979 & 1.863 & 0.003 & 0.002 & 0.002 \\
\hline Amino acid & Glycine & 10.101 & 176.000 & 0.877 & 0.787 & 1.147 & 0.083 & 0.096 & 0.002 \\
\hline- & Phosphoric acid & 9.693 & 179.831 & -0.270 & -0.974 & -1.334 & 0.004 & $<.001$ & $<.001$ \\
\hline- & Fumaric acid & 10.535 & 244.900 & 1.004 & 1.344 & 1.298 & 0.024 & 0.070 & 0.004 \\
\hline- & Urea & 9.258 & 70.012 & 0.347 & 0.792 & 1.251 & 0.194 & 0.034 & 0.002 \\
\hline Carbohydrates & glycerol & 9.657 & 218.003 & 0.900 & 0.777 & 0.987 & 0.001 & 0.001 & $<.001$ \\
\hline Carbohydrates & Glucose & 17.221 & 332.097 & 0.496 & 0.643 & 0.951 & $<.001$ & 0.012 & 0.002 \\
\hline Carbohydrates & Galactose & 17.501 & 337.081 & -0.299 & -1.039 & -0.872 & 0.021 & 0.039 & 0.045 \\
\hline Lipid & $\beta$-Hydroxybutyric acid & 8.091 & 191.015 & -1.532 & -1.488 & -1.111 & 0.001 & 0.002 & 0.012 \\
\hline Lipid & Palmitic acid & 18.161 & 144.098 & -0.699 & -1.179 & -1.059 & 0.014 & $<.001$ & $<.001$ \\
\hline Lipid & Oleic acid & 19.861 & 144.990 & -0.905 & -0.636 & -0.708 & 0.005 & 0.015 & 0.031 \\
\hline Lipid & Oleic acid amide & 21.036 & 91.000 & -0.447 & -1.278 & -1.685 & 0.050 & 0.001 & $<.001$ \\
\hline Lipid & Octadecanamide & 21.137 & 240.062 & -0.673 & -0.548 & -0.571 & 0.002 & 0.043 & 0.039 \\
\hline Lipid & Cholesterol & 27.835 & 255.041 & -0.556 & -1.675 & -3.371 & 0.025 & 0.002 & $<.001$ \\
\hline Lipid & Linoleic acid & 19.747 & 339.103 & 1.023 & 0.810 & 1.170 & 0.008 & 0.010 & 0.037 \\
\hline Lipid & Stearic acid & 19.929 & 341.111 & 1.366 & 0.563 & 0.765 & 0.004 & 0.078 & 0.040 \\
\hline
\end{tabular}

${ }^{1} \mathrm{CON}, 2.5 \%, 5.0 \%$, and 7.5\% mean that supplementation of SL was $0 \%, 2.5 \%, 5.0 \%$, and $7.5 \%$ replaced the equivalent amounts of wheat straw, respectively.

${ }^{2} \mathrm{RT}$ : retention time

${ }^{3} \mathrm{~m} / \mathrm{z}$ : mass-to-charge ratio

${ }^{4}$ fold: means the value of $\log _{2}$ (ratio of mean peak areas), positive and negative values indicated upregulated and downregulated between two groups

${ }^{5} P$ : independent $t$-test for two groups. 
Various metabolites between CON and SL groups were subjected to MetaboAnalyst 3.0 software, which revealed their association with the metabolic pathways. It was found that differential metabolites between CON and 2.5\% SL group were involved in the metabolisms of glycerolipid, butanoate, alanine, aspartate and glutamate, taurine and hypotaurine, linoleic acid, fatty acid, primary bile acid, tricarboxylic acid and steroid hormone biosyntheses (Figure 2). Differential metabolites between CON and 5.0\% SL and 7.5\% $\mathrm{SL}$ that are responsible for the pathways were presented in Figure 2. Moreover, nine pathways, including the metabolisms of glycerolipid, butanoate, alanine, aspartate and glutamate, taurine and hypotaurine, linoleic acid, and fatty acid, and in the biosyntheses of primary bile acid and steroid hormone were shared in the three comparisons. These pathways were filtered out by false discovery rate less than 0.05 having an impact more than 0 .
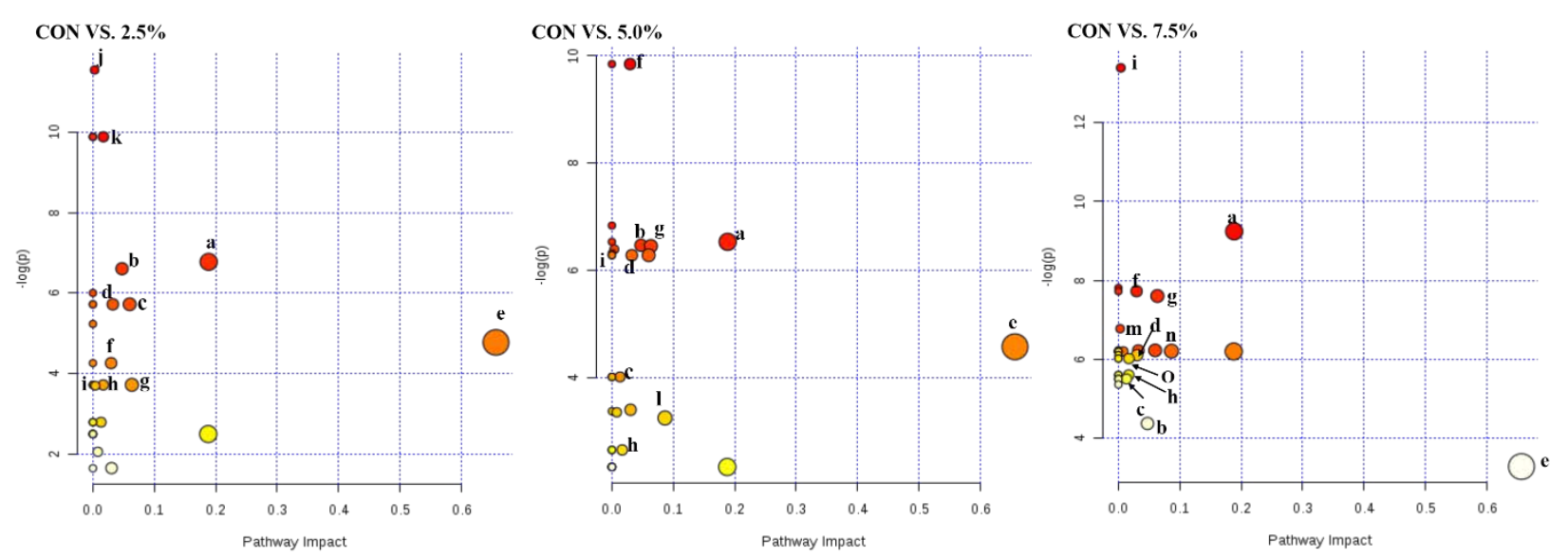

Figure 2 Pathway analysis of differential metabolites between four groups with MetaboAnalyst.

The $x$-axis represents the pathway impact, and y-axis represents the pathway enrichment. Larger sizes and darker colours represent higher pathway enrichment and higher pathway impact values, respectively.

CON, 2.5\%, 5.0\%, and 7.5\% mean that supplementation of SL was $0 \%, 2.5 \%, 5.0 \%$, and $7.5 \%$ replaced the equivalent amounts of wheat straw, respectively.

CON versus $2.5 \%=$ differential metabolites between CON and $2.5 \%$ treatment. CON versus $5.0 \%=$ differential metabolites between CON and 5.0\%. CON versus 7.5\% = differential metabolites between CON and 7.5\%.

(a) glycerolipid metabolism; (b) butanoate metabolism; (c) alanine, aspartate and glutamate metabolism; (d) taurine andhypotaurine metabolism; (e) linoleic acid metabolism; (f) fatty acid metabolism; (g) primary bile acid biosynthesis; (h) tricarboxylic acid (TCA cycle); (i) steroid hormone biosynthesis; (j) galactose metabolism; (k) starch and sucrose metabolism; (I) pentose phosphate pathway; (m) galactose metabolism; ( $\mathrm{n}$ ) pentose phosphate pathway; and (o) starch and sucrose metabolism.

\section{Discussion}

To improve the digestibility of food and food intake, natural food additives are commonly used for raising animals (Fang et al., 2008). Studies have shown that plant extracts can improve food intake and food digestibility in ruminants (Prakash et al., 2010; Velagapudi et al., 2010). The leaf and fruit of sea-buckthorn can improve the average daily gain and feed conversion in monogastric animals (Zhao et al., 2012). Seabuckthorn leaves are rich in flavonoids, which have been found to increase ruminant food intake and digestibility. This might be due to the fact that the extracts can improve the palatability of the diet, while changing rumen microflora can help regulate intestinal flora (Windisch et al., 2008; Xie et al., 2010). In the present study, a higher ADG was observed in the SL-supplemented diets compared with the CON. Presumably, the high doses of SL increased feed intake and indicated that SL improved growth and feed conversion rate.

The function of tissues and organs and the nutritional status of bodies are reflected in serum biochemical indicators (Williams et al., 1997). This concept has helped to establish that SL improved growth performance in the experimental animals. Serum TP is made up of albumin and globulin. High TP content enhances metabolism and immunity, and promotes health and growth in animals. The concentration of serum TP is believed to be associated with the protein supply and growth performance of animals. The serum UN content reflects the balance between the metabolism of protein and amino acid, and decreases if the balance of amino acid is good in animals (Baumhoer et al., 2011). In this study, increased levels of seabuckthorn leaves showed a linear increase in TP $(P<0.01)$, and UN was lower than in the control group. This 
indicated that SL promotes protein biosynthesis and improves growth and feed conversion rates (Velagapudi et al., 2010). Glucose is the main source of energy, which is positively correlated with the growth rate. The current results showed that the concentration of glucose in SL treated animals was increased. It further indicated that SL could promote energy metabolism and weight gain. Creatinine is a small molecular substance that can be filtered through the glomerulus and is rarely absorbed in the renal tubules. Thus the creatinine produced in the body every day, is almost completely excreted with the urine, and is generally not affected by the amount of urine. When renal insufficiency occurs, creatinine accumulates in the body and becomes a harmful toxin. This affects the metabolism of digestive and respiratory systems. In the present study, no difference was found in plasma concentration of creatinine among treatments. This finding indicates that SL had no adverse effects on renal function. According to Ali et al. (2012), sea-buckthorn does not produce toxicity, even at the highest dose. In the present study, the concentration of TC decreased linearly with increasing level of SL. A similar TC decreasing effect was found by Pichiah et al. (2012). This might be due to the dynamic balance of components in the serum. The concentration of cholesterol increased with TP concentration. In common, cholesterol is transported to the tissues in the form of LDL-C in the blood. In the SL groups, increased LDL-C indicates that SL promotes cholesterol metabolism, thereby regulating lipid metabolism.

Metabolomics provides a powerful approach to delineating the global metabolic profiling of living organisms (Patti et al., 2012). It can also comprehensively reveal the change rule and related mechanism of the biosystem that are affected by exogenous substances (Cheng et al., 2017). In the present study, comprehensive analyses were performed of the changes in the metabolites in serum metabolic profiling. This helped to reveal alterations in the body's metabolism when lambs were on the SL diet.

The present study not only detected the different metabolites between the CON and SL diets, but also pinpointed the pathways where those metabolites were active. The metabolites involve a variety of metabolic pathways, including the TCA, steroid hormone biosynthesis, and metabolism of amino acids and fatty acids. All these could be regarded as the most important pathways associated with the metabolic changes in the lambs fed SL diets. So, comprehensive and essential metabolic changes were established in the lambs fed with SL diets.

SL supplementation in the diets of the experimental lambs increased the content of fumaric acid. This acid has been considered as a critical intermediary metabolite in the TCA cycle. Therefore, it implied that supplementation of SL caused a change in energy metabolism. In this study, the concentrations of alanine, glycine, and valine were increased with the addition of SL. In the process, glycogenic amino acid, alanine and glycine can be metabolized to pyruvate, and valine can be converted into succinate coenzyme A. All these enter into the TCA cycle and gluconeogenesis to produce energy (Pilviet al., 2008). Moreover, valine is one of the branched-chain amino acids (BCAA), and its increasing evidenced that BCAAs play important roles in regulating the lipid metabolism (Ying et al., 2012; Nishimura et al., 2010; Xiao et al., 2016). In this study, the concentration of glycine, as a critical metabolite in the $\mathrm{Y}$-glutamyl cycle, increased with the addition of SL. This suggested that the $Y$-glutamyl cycle was enhanced and oxidative stress damage was reduced (Zhang et al., 2012). Similarly, Du et al. (2017) confirmed that sea-buckthorn paste has potent antioxidant activities in vitro and in vivo. The phenomenon might have delayed the kidney damage caused by oxygen free radicals. A protection towards these were given by adjusting the kidney antioxidant enzymes $\mathrm{Na}^{+}-\mathrm{K}^{+}$adenosine triphosphatase, and lipid peroxide products (e.g. malondialdehyde and nitric oxide). Hence, the increased glycine can improve the antioxidant ability of the body and is beneficial to the health of Altay lamb. The glucose level was increased in metabolomic analyses of serum samples in the SL groups compared with CON. The normal source of energy in the body is supplied by glucose oxidation through aerobic respiration (Sun et al., 2017). This result reflected that the supplementation of SL has an effect on the energy metabolism of the Altay lamb.

On the one hand, saturated fatty acids bring beneficial health effects through reducing plasma TG, causing a moderate reduction in blood pressure and regulating cholesterol metabolism (Ruxton et al., 2010; Sutter et al., 2012). On the other hand, linoleic acid is an unsaturated fatty acid (UFA) and one of the two essential fatty acids. In the present research, the level of linoleic acid was increased in SL groups, compared with the CON. So, it suggests that, Altay lamb cannot synthesize it from other food components.

\section{Conclusion}

The daily gain and serum content of TP, TC, and LDL-C increased gradually with the supplementation of SL, while the content of UN was reduced. The high content of SL increased the HDL-C concentration in Altay lamb. The dietary supplementation of SL altered multiple metabolic pathways, including the TCA cycle and the metabolism of amino acids, fatty acids, and steroids. This study has allowed a better understanding of the effects of SL on Altay lamb and provided a theoretical basis for the development and utilization of seabuckthorn leaves as an additive for ruminant production. Further studies are warranted to better define the 
effects of sea-buckthorn leaves in anti-oxidation performance and lipid metabolism of ruminants.

\section{Acknowledgements}

This research was partially supported by grant of the National Key R\&D Program of China (2017YFD0500500 and 2018YFD0502100) and National Modern Mutton Sheep Industry technology system (nycytx-39).

\section{Authors' Contributions}

WJZ, CYG, and CXN contributed to the idea, design and execution of the study. LYF and NJL contributed equally to the write-up of the final manuscript. YFL, and SZT assisted in all lamb procedures for the experiment. GTH, WQW, and WXG performed the samples analysis. NJL and LYF were responsible for the statistical analysis.

\section{Conflict of Interest Declaration}

The authors declare that there was no conflict of interest.

\section{References}

Agriculture Research Council, 1990. Feeding standards for Australian livestock. Ruminant sub-Committee. ARC, CSIRO, Melbourne, Australia.

Ali, R., Ali, R., Jaimini, A., Nishad, D. K., Mittal, G. \&Chaurasia, O.P., 2012. Acute and sub-acute toxicity and efficacy studies of hippophaerhamnoides based herbal antioxidant supplement. Indian J. Pharmacol. 44, 504-508.

AOAC. 2000. Association of Official Analytical Chemists, 17th edition. AOAC International, Arlington, VA, USA.

Baumhoer, D., Elsner, M., Smida, J., Zillmer, S., Rauser, S. \& Schoene, C., 2011. Crip1 expression is correlated with a favorable outcome and less metastases in osteosarcoma patients. Oncotarget. 2, 970-975.

Beveridge, T., Li, T.S., Oomah, B.D. \& Smith, A., 1999. Sea buckthorn products: Manufacture and composition. J. Agric. Food Chem. 47, 3480-3488.

Chen, W., Su, X., Zhang, H., Sun, K., Ma, R. \& Chen, X., 2010. High genetic differentiation of Hippophaerhamnoides ssp. yunnanensis (Elaeagnaceae), a plant endemic to the Qinghai-Tibet Plateau. Biochem. Genet. 2010, 48, 565.

Cheng, J., Huang, S., Fan, C., Zheng, N., Zhang, Y. \& Li, S., Wang, J., 2017. Metabolomic analysis of alterations in lipid oxidation, carbohydrate and amino acid metabolism in dairy goats caused by exposure to aflotoxin b1. Journal of Dairy Research. 84(04), 401-406.

Du Leilei., Hu Xiaoxin., Chen Chu., KuangTingting., Yin Hengfu. \& Wan Li., 2017. Seabuckthorn paste protects lipopolysaccharide-induced acute lung injury in mice through attenuation of oxidative stress. Oxidative Medicine and Cellular Longevity. 2017, 1-9.

Fang, X.K., Gao, J. \& Zhu, D. N., 2008. Kaempferol and quercetin isolated from euonymus alatus improve glucose uptake of 3t3-I1 cells without adipogenesis activity. Life Sci.82, 615-622.

Guliyev, V.B., Gul, M. \& Yildirim, A., 2004. Hippophaerhamnoides I.: chromatographic methods to determine chemical composition, use in traditional medicine and pharmacological effects. J. Chromatogr. B. 812, 291-307.

Gupta, A., Kumar. R., Pal. K., Banerjee, P.K. \& Sawhney, R.C., 2005. A preclinical study of the effects of seabuckthorn (Hippophaerhamnoides L.) leaf extract on cutaneous wound healing in albino rats. Int. J. Low. Ext. Wound. 4, 8892.

Heinz, C. \&Barbaza, M., 1998. Environmental changes during the late glacial and postglacial period in the central Pyrenees (France): New charcoal analysis and archaeological data. Rev. Palaeobot. Palynol. 104, 1-17.

Krejcarová, J., Straková, E., Suchý, P., Herzig, I. \&Karásková, K., 2015. Sea buckthorn (Hippophaerhamnoides L.) as a potential source of nutraceutic and its therapeutic possibilities - A review. Acta Veterinaria Brno. 84, 257-268.

Li, S.C.T., Beveridge, H.J.T. \& Drover, C.G.J., 2007. Phytosterol content of sea buckthorn (hippophaerhamnoides I.) seed oil: Extraction and identification. Food Chem. 101, 1633-1639.

Liu, C.W, Li, Y., Zuo, J.G, Jin, C.M. \& Shi, Y.L., 2008. Effect of sea buckthorn extracts on growth and fat metabolism of weaning piglets. Feed Industry Magazine. 8, 6-8 (in China).

Liu, C., Zu, Z.P., Liu, Y.F., Guo, T.J. \& Dong, H.M., 2012. Diversity and abundance of the rumen and fecal methanogens in Altay sheep native to Xinjiang and the influence of diversity on methane emissions. Arch. Microbiol. 194, 53-61.

Nicholson, J.K., Lindon, J.C. \& Holmes, E., 1999. Metabonomica: Understanding the metabolic responses of living systems to pathophysiological via multivariate statistical analysis of biological NMR spectroscopic data. Xenobiotica. 29, 1181-1189.

Nie, C.X., Zhang, W.J., Wang, Y.Q., Liu, Y.F., Ge, W.X. \& Liu, J.C., 2015. Tissue lipid metabolism and hepatic metabolomic profiling in response to supplementation of fermented cottonseed meal in the diets of broiler chickens. J Zhejiang Univ-SC B. 16, 447-55.

Nishimura, J., Masaki, T., Arakawa, M., Seike, M. \& Yoshimatsu, H., 2010. Isoleucine prevents the accumulation of tissue triglycerides and upregulates the expression of paralpha and uncoupling protein in diet-induced obese mice. J. Nutr. 140, 496-500.

Oresic, M., 2009. Metabolomics, a novel tool for studies of nutrition, metabolism and lipid dysfunction. Nutr. Metab. Cardiovasc. Dis. 19, 816-824.

Patti, G.J., Yanes, O.\&Siuzdak, G., 2012. Innovation: metabolomics: The apogee of the omics trilogy. Nat. Rev. Mol. Cell Biol., 13(4), 263-269.

Pichiah, P. B., Moon, H. J., Park, J. E., Moon, Y. J. \& Cha, Y. S., 2012. Ethanolic extract of sea buckthorn (hippophaerhamnoides I) prevents high-fat diet-induced obesity in mice through down-regulation of adipogenic and lipogenic gene expression. Nutrition Research. 32(11), 856-864. 
Pilvi, T.K., Seppanenlaakso, T., Simolin, H., Finckenberg, P., Huotari, A. \& Herzig, K. H., 2008. Metabolomic changes in fatty liver can be modified by dietary protein and calcium during energy restriction. World J. Gastroenterol. 14, 4462-4472.

Prakash, H., Bala, M., Ali, A. \& Goel, H.C., 2010. Modification of gamma radiation induced response of peritoneal macrophages and splenocytes by hippophaerhamnoides (rh-3) in mice. J. Pharm. Pharmacol. 57, 1065-1072.

Rousi, A., 1971. The genus Hippophae L. A taxonomic study. NederlandsTijdschriftVoorTandheelkunde. 84, $408-413$.

Ruxton, C.H.S., Reed, S.C., Simpson, M.J.A. \& Millington, K.J., 2010. The health benefits of omega-3 polyunsaturated fatty acids: Areview of the evidence. J. Hum. Nutr. Diet. 17, 449-459.

Srivastava, R.B., Korekar, G. \&Stobdan, T., 2013. Nutritional attributes and health application of sea buckthorn (hippophaerhamnoides I.) - a review. Curr. Nutr. Food Sci. 9, 151-165.

Suomela, J.P.A., M., Yang, B., Vasankari, T. \& Kallio, H., 2006. Absorption of flavonols derived from sea buckthorn (HippophaërhamnoidesL.and their effect on emerging risk factors for cardiovascular disease in humans. J. Agric. Food Chem. 54, 7364-7369.

Sun, L., Zhang, H., Fan, Y., Guo, Y., Zhang, G. \&Nie, H., 2017. Metabolomic profiling in umbilical venous plasma reveals effects of dietary rumen-protected arginine or n-carbamylglutamate supplementation in nutrient-restricted $\mathrm{Hu}$ sheep during pregnancy. Reprod. Domest. Anim. 52, 376-388.

Sutter, H. \&Wijkman, N., 2012. Fish oil supplementation alters the plasma lipidomic profile and increases long-chain PUFAS of phospholipids and triglycerides in healthy subjects. Plos One. 7, e42550.

Van Soest, P.J., Robertson, J.B. \& Lewis, B.A., 1991. Methods for dietary fiber, neutral detergent fiber, and nonstarch polysaccharides in relation to animal nutrition. J. Dairy. Sci. 74, 3583-3597.

Velagapudi, V.R., Hezaveh, R., Reigstad, C.S., Gopalacharyulu, P., Yetukuri, L. \& Islam, S., 2010. The gut microbiota modulates host energy and lipid metabolism in mice. J. Lipid. Res. 51, 1101-1112.

Wang, X., Liu, J.R., Zhang, X.H., Zhao, S.M., Zou, K., Xie, J.M., Wang, X.X., Liu C.Y., Wand J.L. \& Wang, Y.Z., 2018. Seabuckthorn berry polysaccharide extracts protect against acetaminophen induced hepatotoxicity in mice via activating the nrf-2/ho-1-sod-2 signaling pathway. Phytomedicine. 38, 90-97.

Williams, N.H., Stahly, T.S. \& Zimmerman, D.R., 1997. Effect of chronic immune system activation on body nitrogen retention, partial efficiency of lysine utilization, and lysine needs of pigs. J. Anim. Sci. 75, 2472-2480.

Windisch, W., Schedle, K., Plitzner, C. \&Kroismayr, A., 2008. Use of phytogenic products as feed additives for swine and poultry. J. Anim. Sci. 86, 140-8.

Wood, J.T.\& Williams, J.S., Pandarinathan, L., Janero, D.R., Lammikeefe, C.J. \&Makriyannis, A., 2010. Dietary docosahexaenoic acid supplementation alters select physiological endocannabinoid-system metabolites in brain and plasma. J. Lipid. Res. 51, 1416-1423.

Xiao, F., Du, Y., Lv, Z., Chen, S., Zhu, J. \& Sheng, H., 2016. Effects of essential amino acids on lipid metabolism in mice and humans. J. Mol. Endocrinol. 57, 223.

Xie, Y., Zeng, X., Li, G., Cai, Z., Ding, N. \& Ji G., 2010. Assessment of intestinal absorption of total flavones of hippophaerhamnoides I. in rat using in situ absorption models. Drug Dev. Ind Pharm. 36, 787-794.

Ying, D., Meng, Q., Qian, Z. \& Guo, F., 2012. Isoleucine or valine deprivation stimulates fat loss via increasing energy expenditure and regulating lipid metabolism in wat. Amino Acids. 43, 725-734.

Yildiz, H., Sengul, M., Celik. F., Ercisli, S. \&Duralija, B., 2012. Bioactive content of sea buckthorn (hippophaerhamnoides I.) berries from turkey. Agric. Conspec. Sci. 77, 818-819.

Yuan, H.B., Zhu, X.P., Wang, W.J., Meng, L., Chen, D.Y. \& Zhang, C., 2016. Hypoglycemic and anti-inflammatory effects of sea buckthorn seed protein in diabetic ICR mice. Food. Funct. 7, 1610-1620.

Zhang, J., Shi, H.T., Wang, Y.J., Li, S., Cao, Z.J., He, Y. \& Zhang, H., 2017. Effect of dietary forage to concentrate ratios on dynamic profile changes and interactions of ruminal microbiota and metabolites in Holstein heifers. Front. Microbiol. 2017,8, 2206.

Zhang, W.C., Shyhchang, N., Yang, H., Rai, A., Umashankar, S. \& Ma, S., 2012. Glycine decarboxylase activity drives non-small cell lung cancer tumor-initiating cells and tumorigenesis. Cell. 148, 259-272.

Zhao, P., Wang, SL., Liang, C., Wang, YW., Wen, PJ., Wang, F. \& Qin, GQ., 2017. Acute and subchronic toxicity studies of seabuckthorn (hippophaerhamnoides I.) oil in rodents. Regul. Toxicol. Pharmacol. 91, 1-35.

Zhao, W., Chen, X., Liu, H.N., Yang, W.W., Wang, M.H. \& Li, Y., 2012. Effects of flavones from sea buckthorn leaves on growth performance and carcass quality of broilers. Chinese Journal of Animal Nutrition. 24, 117-123 (in Chinese). 